\title{
Establishment and Application of Prostate Cancer Circulating Tumor Cells in the Era of Precision Medicine
}

\author{
Yoon Seok Suh, Jae Young Joung, Sung Han Kim, Ho Kyung Seo, \\ Jinsoo Chung, and Kang Hyun Lee \\ Center for Prostate Cancer, Hospital, National Cancer Center, Goyang, Gyeonggi-do, Republic of Korea \\ Correspondence should be addressed to Kang Hyun Lee; uroonco@ncc.re.kr
}

Received 13 May 2017; Accepted 27 August 2017; Published 5 November 2017

Academic Editor: Gianluigi Taverna

Copyright (C) 2017 Yoon Seok Suh et al. This is an open access article distributed under the Creative Commons Attribution License, which permits unrestricted use, distribution, and reproduction in any medium, provided the original work is properly cited.

Prostate cancer (PC) is the second most common cancer in men and is the fifth leading cause of cancer-related deaths worldwide. Additionally, there is concern for overdiagnosis and overtreatment of PC. Thus, selection of an appropriate candidate for active surveillance as well as more accurate and less invasive tools for monitoring advanced PC is required. Circulating tumor cells (CTCs) have emerged as a liquid biopsy tool; there have been several reports on its role, technologies, and applications to various cancers, including PC. Liquid biopsy using CTCs has been gaining attention as a minimal invasive tool for investigation of biomarkers and for prognosis and assessment of response to therapies in patients with PC. Because of the lower invasiveness of liquid biopsy using CTCs, it can be performed more frequently; accordingly, personalized disease status can be successively determined at serial time points. CTC analysis enables detection of genomic alterations, which is drug-targetable, and it is a potential tool for monitoring response to therapeutic agents in patients with PC. This review focuses on the characteristics, technologies for analysis, and advantages and disadvantages of CTCs as a liquid biopsy tool and their application in PC. Finally, we propose future directions of CTCs.

\section{Introduction}

Prostate cancer (PC) is the second most common cancer in men and is the fifth leading cause of cancer-related deaths worldwide [1]. In the United States, PC is the second leading cause of cancer-specific deaths in men, and approximately 26,120 PC-related deaths were recorded in 2016 [2]. Although PC has a high prevalence among cancers as stated above, there is also a concern about overdiagnosis and overtreatment of PC. With an emerging concept of indolent PC [3], active surveillance, prescribed in several guidelines for active surveillance eligibility, of localized PC with low malignant potential is gaining wide acceptance [4-17]. However, after using the current method of prostate biopsy for diagnosing PC, there is a possibility of significant upgrade of PC [18]. Additionally, the patient undergoing active surveillance needs to undergo repeated prostate biopsies to determine disease progression. However, prostate biopsy by transrectal or transperineal approach is an invasive procedure and occasionally associated with morbidity, such as hematuria, hematochezia, acute urinary retention, urinary tract infection, and bacteremia [19]. Thus, to select an appropriate candidate for active surveillance, more accurate and less invasive tools for monitoring PC are required.

On the contrary, PC at an advanced stage is a lethal disease; however, several treatment strategies are available for locally advanced or metastatic PC, and overall survival (OS) in patients with even metastatic castration-resistant PC (CRPC) has been improved with the development of several promising drugs [20]. Quantitation of therapeutic response in metastatic CRPC is difficult due to lack of tools [21]. In a recent meta-analysis [22], circulating tumor cells (CTCs) positively indicated poor prognosis and CTC counts were a potential independent prognostic factor of survival rate in patients with CRPC. Hence, early detection of drug response to specific therapeutics and recurrence using CTCs would result in enhancing treatment outcome and reducing socioeconomic burden in treating PC.

Liquid biopsy using CTCs is gaining attention as a minimal invasive tool for investigation of biomarkers. Because of 
less morbidity of liquid biopsy using CTCs, it can be performed more frequently; accordingly, personalized disease status can be successively achieved at serial time points [23]. This is advantageous during treatment period for measuring tumor burden and early detection of recurrence or resistance [24]. Changes in CTC counts during systemic therapy can be used as a tool for monitoring treatment response [25].

Liquid biopsy using CTCs can aid in selection of an appropriate candidate for active surveillance and monitoring response to active surveillance or therapies and recurrence. Investigation of CTCs to discover new, more effective, and less invasive biomarkers is expected to contribute to reducing morbidity and costs associated with PC, the prevalence of which is increasing. In this review, we discussed the technology, advantages and disadvantages, applications, and the future direction of CTCs in PC.

\section{Circulating Tumor Cells}

Historically, CTCs were observed for the first time by Thomas Ashworth in the blood of a cadaver with metastatic cancer [26]. CTCs in the peripheral blood are originated from the primary tumor or metastatic foci and are circulated along the blood vessels and spread throughout the body [27]. They are involved in cancer metastasis, and protein expression and localization of CTCs at the cellular level were highly heterogeneous, which reflects the primary tumor and metastatic site [28]. CTCs have been detected in several malignancies, such as those of the prostate, breast, colon, lung, kidney, and bladder [29-37].

In the urological field, especially, elevation of CTC level in the peripheral blood was noted in patients with advanced renal cell carcinoma (RCC) and was associated with an aggressive phenotype [38]. CTC level in the peripheral blood was correlated with lymph node involvement and metastasis. CTC enumeration in the peripheral blood and expression of vimentin in CTCs were correlated with RCC progression [33]. CTCs were also detected in patients with metastatic bladder cancer $[34,35]$. CTC levels were higher in the peripheral blood of patients with bladder cancer than in the control group. Quantification of CTCs using the expression of folate receptor $\alpha$ showed $82 \%$ sensitivity and $62 \%$ specificity in case of bladder cancer detection [36]. Enumeration of CTCs in the peripheral blood was an early predictor of bladder cancer recurrence and overall cancer-specific mortality [37].

There are several types of CTCs. Traditional CTCs were confirmed with a viability test, nuclear localization of cytokeratins, and an absence of CD45, which implies epithelial and nonhematopoietic origins, respectively [39]. They are larger cells with a subcellular feature or irregular morphology. Cytokeratin negative (CK-) CTCs or cancer stem cells undergo epithelial-mesenchymal transition (EMT) [40]. CK- CTCs are considered to have genomic profile or gene expression specific to cancer and morphology similar to a cancer cell and are prone to resistance and metastasis. Nuclear fragmentation or cytoplasmic bleb associated with apoptosis of CTCs was identified with Epic Sciences technology [40]. Efficacy of therapy can be checked by serial measurement of the ratio of traditional CTCs to apoptotic CTCs. Small CTCs are $\mathrm{CD} 45-$ and $\mathrm{CK}+$, and their morphology is similar to that of white blood cells [41]. CTC cluster is a bounded form of two or more CTCs $[42,43]$. The CTC cluster is thought to contain CK- or small CTCs. Aceto et al. reported that this cluster is related to increased risk of metastasis and poor prognosis [42].

Small CTCs are related to differentiation into small cell carcinomas and progressive disease, which need a different treatment strategy.

Despite therapeutic and prognostic role of CTCs, detecting CTCs is difficult because they are present in small numbers [44]. The detection frequency of CTCs is $1-10$ CTCs $/ \mathrm{mL}$ of whole blood from patients with metastatic cancer [45]. Thus, fine and precise technologies with high sensitivity and specificity are required to detect various CTC subtypes in patients with numerous cancer types $[40,46]$.

\section{Technologies Based on CTC Analysis}

Analysis of CTCs includes their isolation and enrichment, detection, enumeration, and molecular characterization [47]. To isolate and enrich CTCs using filtration devices, physical features, such as size, electrical charge, and density, are considered [48].

The CellSearch ${ }^{\circledR}$ system (Veridex, Raritan, NJ, USA) was approved by the Food and Drug Administration (FDA) for monitoring patients with metastatic PC [49]. Currently, this is the only test for detecting CTCs that has received approval from the FDA. Briefly, $7.5 \mathrm{~mL}$ peripheral blood is sampled in an EDTA tube, centrifuged, and placed in the preparation system that enriches the tumor cells immunomagnetically with magnet and ferrofluid nanoparticles. CTCs of epithelial origin can be counted with a nuclear stain and a fluorescent antibody conjugate against EpCAM+; CD45-; and cytokeratins $8,18+$, and/or $19+$ in the peripheral blood $[43,50]$. For becoming CTCs, cells should possess a nucleus with diameter larger than $5 \mu \mathrm{m}$ and should be negative for the CD45 marker and positive for CK. If five or more CTCs are found, the result is considered positive. This test has a detection limit of 1 CTC/7.5 mL whole blood with $93 \%$ recovery capacity.

Although it is the only method approved by the FDA, there are several limitations. Specific equipment-the CellTracks AutoPrep and the CellTracks Analyzer II unit (Veridex LLC, Raritan, NJ, USA) - is required to perform the test. Considering the sensitivity and specificity, CTCs are not yet utilized practically; therefore, analyzing content in CTC, such as that of miRNAs, to detect cancer biomarkers is gaining interest [51]. Using antibodies that can recognize tumor marker may be biased due to requirement for enough expression of protein on the cell surface [52]. Some tumors do not express EpCAM and CKs, which can be downregulated during EMT [52].

Maintrac method employs microscopy for identifying CTCs [53]. For analysis, cells are prepared with single centrifugation and erythrocyte lysis. The processes of purifying or enriching cells can be omitted with this method. Instead, cells are identified among the mixture of blood components. EpCAM antibody is used for identification of cells. With this method, live EpCAM+ propidium-excluding cells can 
be counted as cancer cells. The suspension is analyzed by fluorescence microscopy, and the events are automatically counted. Previous studies demonstrated that adding CK- or CD45- specific antibodies does not have any merit $[54,55]$. Maintrac uses the dynamics of cell count, and varying tumor cell number is an indicator of cancer activity. This method was used for determining the outcome of chemotherapy and for monitoring the response to hormone therapy [54, 5658]. Additionally, early detection of cancer recurrence was verified with this method $[59,60]$.

However EpCAM+ cells can be detected in the peripheral blood when inflammation disease or skin burns are present [61]. Thus, diagnosis of cancer by EpCAM+ cells is not appropriate.

CTCs can be separated based on antigen-antibody interactions. Antibodies against tumor specific biomarkers, such as PSA, Her2, and EpCAM, are used. Magnetic-activated cell sorting (MACS) is a commonly used separation method based on magnetic nanoparticles. Microfluidic separation and immunomagnetic assay were used in previous studies [62-66]. Viruses with oncolytic features were used for detecting CTCs [67]. In other studies, for better control of the magnetic field, magnetic structure with a microscale was implemented [68-70].

A filtering-based method considering cell size was employed to capture CTCs [71]. The ScreenCell method captures CTCs with an isolation device using the drawn peripheral blood for 4 hours [72]. It allows isolation of CTCs by a filtration-based device using the whole blood.

Previous studies reported detection of CTCs by GILUPI $\mathrm{GmbH}$ in vivo $[73,74]$. By inserting a metal wire that is coated with an antibody into a peripheral vein for 30 minutes, CTCs bind to the antibodies. After isolating CTCs, several methods, including immunofluorescence staining and molecular genetics, could be employed [67, 75]. Analyzing higher blood volume for detecting CTCs is an advantage of this method. Viatar CTC Solutions developed a method based on therapeutic oncopheresis that uses a mechanical filtration system for dialysis of CTCs for 4 hours [76].

CTC detection can be performed using RNA- or DNAbased technology with improved sensitivity. AdnaTest kit (Qiagen, Hannover, GE) uses simultaneous amplification and detection of multiple transcripts of circulating RNA or DNA to detect CTCs [77]. This method utilizes multiplex reverse transcription polymerase chain reaction (RT-PCR). In addition, other methods, such as CTC filters, acousticbased separation, and microscopy, could be used to detect CTCs [78-80].

Methods for CTC isolation should allow their identification, enumeration, and characterization. ViewRNA ISH Cell Assays is a method that enables multiplex, single-molecule detection of specific RNA target with in situ hybridization technology [81]. Proprietary probe design allows high sensitivity and specificity using background suppression and branched DNA signal amplification.

After removal of the primary tumor, biopsy of the tumor by tissue typing is not possible [82]. In this case, tissue sections from the primary tumor can be used for typing, and CTC characterization can be performed to identify the tumor phenotypes. FISH assays were used on CTCs and identification of Her2, IGF-1R, Bcl-2, AR status, ERG, and PTEN was performed [83-86].

\section{Advantages and Disadvantages of CTCs as a Liquid Biopsy Tool}

Tissue biopsy is invasive, unsuitable to be performed repeatedly, and unpredictive for understanding effectiveness of treatment, disease progression, and metastasis risk [87]. CTCs can render ongoing information of metastasis reflecting the patient's disease status [83]. CTC detecting method using the peripheral blood is feasible and safe to be performed. Additionally, successive and repeated sampling is available. These characteristics of liquid biopsy allow monitoring the disease status, including progression and response to therapies.

Despite the aforementioned merits of methods for CTC detection, some demerits should be overcome before adopting it practically; several clinical, technical, and biological problems need to be solved. Because tumor is characteristically heterogeneous, revealing the source of CTCs is the most important to understand its clinical usefulness.

Since CTCs are present at low levels in the whole blood, assays with higher sensitivity are required. Droplet digital PCR (ddPCR) is a promising method, but sufficient blood is needed for appropriate analysis. Another hurdle is measuring the changes in CTC counts that might be minute. These demerits should be addressed to consider CTCs as a monitoring marker for cancer.

Since CTCs are extremely rare in the blood, sensitivity and specificity are not enough for accurate detection of CTCs, and enumeration has not been accepted as a method for tumor staging, CTCs cannot be used routinely in clinical practice yet. Despite the presence of various methods for CTC detection, none of them are established to be clinically applicable due to narrow detection spectrum, low purity, and loss of CTCs [116]. Additionally, methods for CTC detection are usually accompanied by complicated processes, long time for CTC detection, and significant costs.

\section{Application of CTCs in PC}

Studies that reported CTC detection in patients with PC are summarized in Table 1. Some studies demonstrated the association of CTCs with biochemical recurrence after radical prostatectomy. In the study with 250 high-risk patients with PC, presence of prostate stem cell antigen (PSCA) mRNA in the peripheral blood was reported to be a significant predictor of biochemical recurrence after radical prostatectomy (HR, 4.549; 95\% CI, 1.685-12.279) [93]. Joung et al. reported that prostate specific membrane antigen (PSMA) mRNA in the peripheral blood was a predictor of biochemical recurrence after radical prostatectomy [95]. Nested RT-PCR assay detecting PSMA mRNA-bearing cells in the peripheral blood was employed to detect CTCs. PSMA mRNA (HR, 3.697; 95\% CI, 1.285-10.634; $P=0.015$ ) was an independent predictor of biochemical recurrence. 


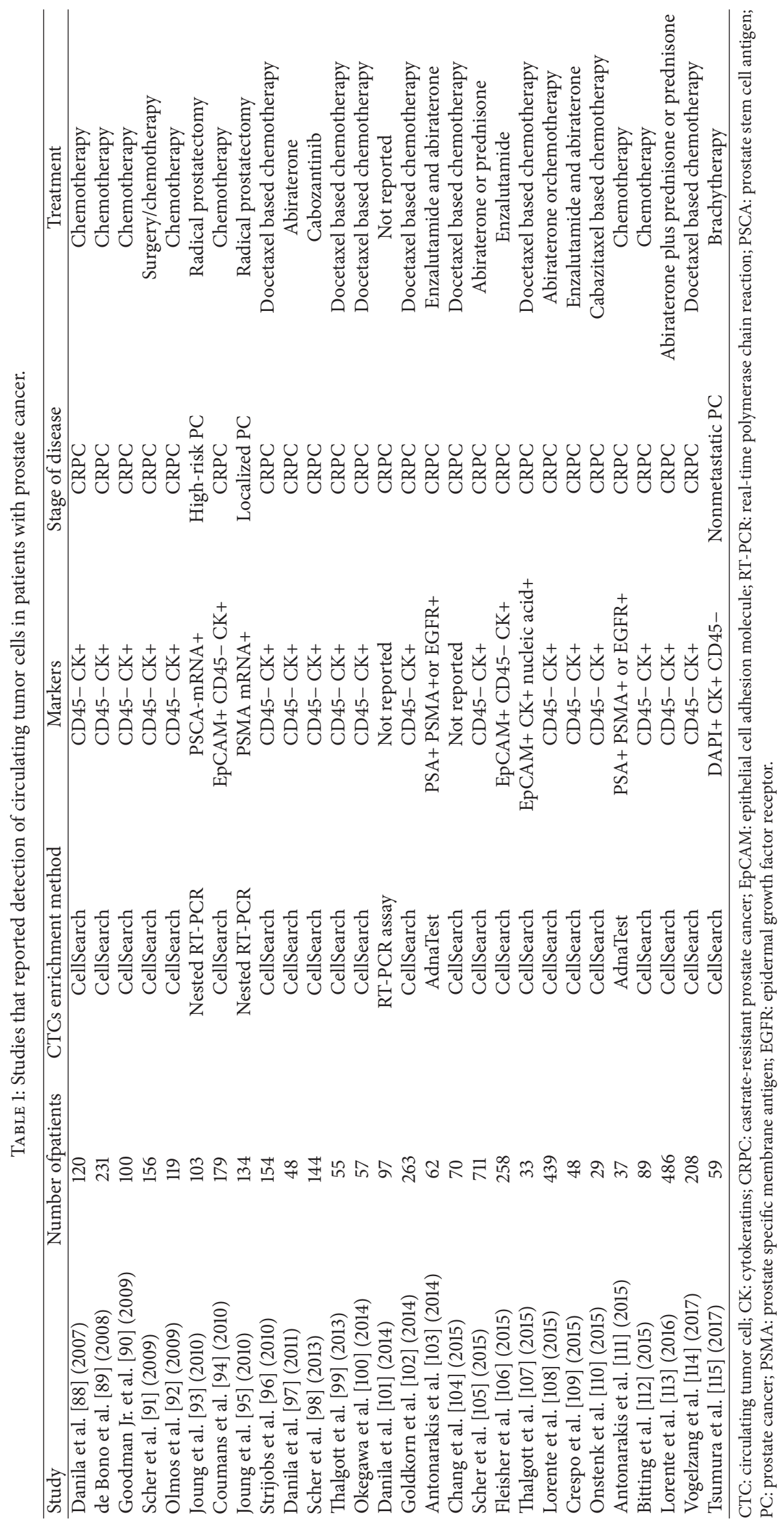


CTCs are often found in patients with mCRPC and it showed a prognostic significance [102]. de Bono et al. reported that elevated level of CTCs was a prognostic factor in patients with mCRPC [89]. Unfavorable group that had 5 or $>5$ CTCs/7.5 mL peripheral blood showed significantly shorter OS (median OS 11.5 versus 21.5 months) than that showed by favorable group ( $\leq 5 \mathrm{CTCs} / 7.5 \mathrm{~mL}$ peripheral blood). In this study, level of CTCs was a stronger predictor of OS than PSA was.

In a phase III clinical study, CTC level elevation after three cycles of docetaxel with lenalidomide chemotherapy in patients with mCRPC predicted poor survival [114]. Scher et al. reported in their phase III trial that level of lactate dehydrogenase and number of CTCs in the whole blood were predictors of OS in patients with MCRPC that had been treated with abiraterone acetate and docetaxel [105]. Twoyear survival of patients with $\geq 5 \mathrm{CTCs} / 7.5 \mathrm{~mL}$ was $2 \%$, while that of patients with $<5$ CTCs/7.5 mL was $46 \%$ (CTCs were counted at 12 weeks). Lorente et al. demonstrated that decline in CTC count by $30 \%$ after treatment from an initial count $\geq 5$ cells $/ 7.5 \mathrm{~mL}$ is independently associated with CRPC OS following chemotherapy and abiraterone treatment [113].

CTCs have emerged as a biomarker in mCRPC that guides therapeutic decisions. For evaluating predictor of resistance to treatments, molecular alterations in androgen receptor (AR) on CTCs were investigated. Antonarakis et al. demonstrated an association of detection of AR splice variant-7 (AR-V7) in CTCs and resistance to AR-targeting treatments in patients with mCRPC [103]. Recently, a realtime CTC-based assay of nuclear AR expression in CTCs of patients with CRPC was developed using CellSearch System [109].

Recently, no significant correlation between detection of AR-V7 positive CTCs and primary resistance to taxane chemotherapy was demonstrated in patients with mCRPC $[111,117]$. Thalgott et al. reported that categorical status of CTC count, which was assessed after a cycle of taxane chemotherapy, was a predictor for progression-free survival and OS in patients with mCRPC [107]. This implies that categorical CTC count can act as a predictor of treatment response to taxane chemotherapy. However, AR-V7 status was not a predictor of response to cabazitaxel $[110,118]$.

\section{Future Directions of CTCs}

Cancer biomarker development using CTCs is a promising and rapidly expanding field. The emergence of ddPCR and next-generation sequencing (NGS) enabled improved detection rate and minimized time and expenses. Gulati et al. reported biomarker panel with an improved sensitivity and specificity compared to those of previous single markers [119]. However, most of the other markers are still experimental; accordingly establishment of these markers is required in the future. For improving accuracy of CTCs as a biomarker for cancer activity, usage of different molecular alteration levels, such as combining proteomics, genomics, and transcriptomics, would be beneficial $[120,121]$.

The analysis technique of CTCs has to be innovated with high selectivity and sensitivity that can be utilized for
CTC purification, downstream CTC characterization, and retaining viable CTCs for ex vivo expansion [122]. Various CTC detection methods may count different subclasses of CTCs, and the best CTCs, which are clinically relevant, have not been established. Thus, the best analysis methods should be investigated for use as a biomarker of cancer and monitoring response to therapies.

\section{Conclusion}

In the era of precision medicine, treatment of PC will be tailored based on behavior of PC in each patient. Liquid biopsy using CTCs is a promising tool as a marker for prognosis and assessment of response to therapies in patients with PC. CTC analysis has a minimal invasive nature; accordingly, it is a suitable follow-up of biopsy, when serial PC behavior is required. CTC analysis enables detection of genomic alterations, which is drug-targetable, and it is a potential tool for monitoring response to therapeutic agents in patients with $\mathrm{PC}$.

The utility of CTCs in patients with CRPC and localized PC after radical prostatectomy has been reported. Identification of gene expression, such as $\mathrm{AR}$ expression variants in CTCs, can be used as promising marker for selection of therapeutics in patients with mCRPC. However, application of CTCs in candidate for active surveillance is not well evaluated; accordingly, development of CTC marker that is specific in patients eligible to current active surveillance criteria is required for reflecting the increasing trend of active surveillance.

Future research on CTCs should be focused on developing a marker for CTCs with improved sensitivity and specificity, prior to their application to the detection of PC. The ideal marker for PC should be expressed on most of the CTCs, but not on other cells in the blood, and its expression should be maintained throughout the course of PC. The effort for using different molecular alteration levels has to be made for improving accuracy of CTCs as well. Finally, the technique used for CTC analysis should be improved to obtain high selectivity and sensitivity for the application of CTCs in PC.

\section{Conflicts of Interest}

The authors declare that they have no conflicts of interest.

\section{Authors' Contributions}

Yoon Seok Suh and Jae Young Joung contributed equally to this work.

\section{Acknowledgments}

The research was granted from National Cancer Center, Republic of Korea (no. 1510170-3).

\section{References}

[1] L. A. Torre, F. Bray, R. L. Siegel, J. Ferlay, and J. LortetTieulent, "Global cancer statistics, 2012," CA: A Cancer Journal for Clinicians, vol. 65, no. 2, pp. 87-108, 2015. 
[2] R. L. Siegel, K. D. Miller, and A. Jemal, "Cancer statistics, 2016," CA: A Cancer Journal for Clinicians, vol. 66, no. 1, pp. 7-30, 2016.

[3] L. J. Esserman, I. M. Thompson, B. Reid et al., "Addressing overdiagnosis and overtreatment in cancer: A prescription for change," The Lancet Oncology, vol. 15, no. 6, pp. e234-e242, 2014.

[4] The National Institute for Health and Clinical Excellence (NICE), "Prostate cancer: diagnosis and management," 2014, https://www.nice.org.uk/guidance/cg175.

[5] I. Thompson, J. B. Thrasher, G. Aus et al., "Guideline for the management of clinically localized prostate cancer: 2007 update," Journal of Urology, vol. 177, no. 6, pp. 2106-2131, 2007.

[6] H. Remmelink, "De 'Richtlijn OSAS bij kinderen"” Nederlands Tijdschrift voor Tandheelkunde, vol. 121, no. 10, pp. 499-505, 2014, http://richtlijnendatabase.nl/richtlijn/prostaatcarcinoom/ algemeen.html.

[7] M. P. Wirth and M. Fröhner, "S3-Leitlinie zur Diagnostik und Therapie des Prostatakarzinoms," Der Onkologe, vol. 18, no. 4, pp. 355-364, 2012.

[8] The Finnish Medical Society Duodecim (FCCG), "Prostate cancer (Eturauhassyöpä)," SCAN, http://www.kaypahoito.fi/web/ kh/suositukset/suositus.2014.

[9] F. D. S. E. Melo, X. Wang, M. Jansen et al., "Poor-prognosis colon cancer is defined by a molecularly distinct subtype and develops from serrated precursor lesions," Nature Medicine, vol. 19, no. 5, pp. 614-618, 2013.

[10] Prostate Cancer Taskforce (PCT), Diagnosis and management of prostate cancer in New Zealand men: recommendations from the Prostate Cancer Taskforce, The New Zealand Ministry of Health, New Zealand, Oceania, 2013, http://www.prostate.org.nz/documents/diagnosismanagement-prostate-cancer-nz-men_(3).pdf.

[11] South East Scotland Cancer Network (SCAN), SCAN guideline for active surveillance (deferred radical treatment) of early, lowrisk, prostate cancer, Scotland, UK, 2015, http://www.scan.scot .nhs.uk/Documents/SCAN\%20Protocol\%20for\%20Active\% 20Surveillance $\% 20$ of\%20Early\%20Prostate\%20Cancer\%20-\% 2017072009.pdf.

[12] Nova Scotia (CCNS). Guidelines for the management of prostate cancer, Cancer Care, Guidelines for the management of prostate cancer, 2006, http://www.cancercare.ns.ca/sitecc/media/cancercare/ProstateGuidelinesFullVersion2006(1).pdf.

[13] Biblioteca de Guias del Practica Clinica del Systema Nacional de Salud [online], Aragon Institute of Health, //, 2008, http://www .guiasalud.es/GPC/GPC_431_Prostate_Ca_ICS_compl_en.pdf.

[14] Services (AHS). Alberta Health Services clinical practice guideline: prostate cancer, Alberta Health, //, 2014, http://www.albertahealthservices.ca/assets/info/hp/cancer/if-hp-cancerguide-gu004-prostate.pdf.

[15] C. Morash, R. Tey, C. Agbassi et al., "Active surveillance for the management of localized prostate cancer: Guideline recommendations," Journal of the Canadian Urological Association, vol. 9, no. 6, pp. 171-178, 2015.

[16] Singapore [online], Singapore Ministry of Health (NCCS). Guidelines on Management of Prostate Cancer. Annals Academy of Medicine, //, 2013, http://www.annals.edu.sg/pdf/ 42VolNo4Apr2013/V42N4p190.pdf.

[17] Cancer Council Australia, "Prostate Cancer Foundation of Australia and Cancer Council Australia PSA Testing Guidelines Expert Advisory Panel. Draft clinical practice guidelines PSA Testing and Early Management of Test-Detected Prostate Cancer," 2015, http://wiki.cancer.org.au/australiawiki/index .php?oldid=106555.
[18] T. H. Kim, H. G. Jeon, S. H. Choo et al., "Pathological upgrading and upstaging of patients eligible for active surveillance according to currently used protocols," International Journal of Urology, vol. 21, no. 4, pp. 377-381, 2014.

[19] W. Song, S. H. Choo, H. H. Sung et al., "Incidence and management of extended-spectrum beta-lactamase and quinoloneresistant escherichia coli infections after prostate biopsy," Urology, vol. 84, no. 5, pp. 1001-1006, 2014.

[20] J. Mateo, S. Carreira, S. Sandhu et al., "DNA-repair defects and olaparib in metastatic prostate cancer," New England Journal of Medicine, vol. 373, no. 18, pp. 1697-1708, 2015.

[21] D. T. Miyamoto and R. J. Lee, "Cell-free and circulating tumor cell-based biomarkers in men with metastatic prostate cancer: Tools for real-time precision medicine?" Urologic Oncology: Seminars and Original Investigations, vol. 34, no. 11, pp. 490-501, 2016.

[22] Y. Zheng, C. Zhang, J. Wu et al., "Prognostic value of circulating tumor cells in castration resistant prostate cancer: a metaanalysis," Urology Journal, vol. 13, no. 6, pp. 2881-2888, 2016.

[23] C. Bettegowda, M. Sausen, R. J. Leary et al. et al., "Detection of circulating tumor DNA in early-and late-stage human malignancies," Science translational medicine, vol. 6, no. 224, Article ID 224ra24-ra24, 2014.

[24] F. Cheng, L. Su, and C. Qian, "Circulating tumor DNA: A promising biomarker in the liquid biopsy of cancer," Oncotarget, vol. 7, no. 30, pp. 48832-48841, 2016.

[25] T. W. Friedlander and L. Fong, "The end of the beginning: Circulating tumor cells as a biomarker in castration-resistant prostate cancer," Journal of Clinical Oncology, vol. 32, no. 11, pp. 1104-1106, 2014.

[26] T. Ashworth, "A case of cancer in which cells similar to those in the tumours were seen in the blood after death," Australasian Medical Journal, vol. 14, no. 3, pp. 146-149, 1869.

[27] M. Riquet, C. Rivera, L. Gibault et al., "Lymphatic spread of lung cancer: Anatomical lymph node chains unchained in zones," Revue de Pneumologie Clinique, vol. 70, no. 1-2, pp. 16-25, 2014.

[28] I. J. Fidler, "The pathogenesis of cancer metastasis: the "seed and soil" hypothesis revisited," Nature Reviews Cancer, vol. 3, no. 6, pp. 453-458, 2003.

[29] R. F. Swaby and M. Cristofanilli, "Circulating tumor cells in breast cancer: a tool whose time has come of age," $B M C$ Medicine, vol. 9, article 43, 2011.

[30] D. C. Danila, M. Fleisher, and H. I. Scher, "Circulating tumor cells as biomarkers in prostate cancer," Clinical Cancer Research, vol. 17, no. 12, pp. 3903-3912, 2011.

[31] F. Tanaka, K. Yoneda, N. Kondo et al., "Circulating tumor cell as a diagnostic marker in primary lung cancer," Clinical Cancer Research, vol. 15, no. 22, pp. 6980-6986, 2009.

[32] B. P. Negin and S. J. Cohen, "Circulating tumor cells in colorectal cancer: Past, present, and future challenges," Current Treatment Options in Oncology, vol. 11, no. 1-2, pp. 1-13, 2010.

[33] A. Di Meo, J. Bartlett, Y. Cheng, M. D. Pasic, and G. M. Yousef, "Liquid biopsy: a step forward towards precision medicine in urologic malignancies," Molecular Cancer, vol. 16, no. 1, 80 pages, 2017.

[34] T. W. Flaig, S. Wilson, A. van Bokhoven et al., "Detection of circulating tumor cells in metastatic and clinically localized urothelial carcinoma," Urology, vol. 78, no. 4, pp. 863-867, 2011.

[35] M. Naoe, Y. Ogawa, J. Morita et al., "Detection of circulating urothelial cancer cells in the blood using the CellSearch system," Cancer, vol. 109, no. 7, pp. 1439-1445, 2007. 
[36] F. Qi, Y. Liu, R. Zhao et al., "Quantitation of rare circulating tumor cells by folate receptor $\alpha$ ligand-targeted PCR in bladder transitional cell carcinoma and its potential diagnostic significance," Tumor Biology, vol. 35, no. 7, pp. 7217-7223, 2014.

[37] M. Rink, F. K. Chun, R. Dahlem et al., "Prognostic role and HER2 expression of circulating tumor cells in peripheral blood of patients prior to radical cystectomy: a prospective study," European Urology, vol. 61, no. 4, pp. 810-817, 2012.

[38] S. Füssel, F. B. Artel, H. Heynemann, P. Fornara, H. Taubert, M. Wirth et al., "Detection of circulating tumor cells from renal carcinoma patients: experiences of a two-center study," Oncology Reports, vol. 14, pp. 895-899, 2005.

[39] E. Racila, D. Euhus, A. J. Weiss et al., "Detection and characterization of carcinoma cells in the blood," Proceedings of the National Academy of Sciences of the United States of America, vol. 95, no. 8, pp. 4589-4594, 1998.

[40] D. Marrinucci, K. Bethel, A. Kolatkar et al., "Fluid biopsy in patients with metastatic prostate, pancreatic and breast cancers," Physical Biology, vol. 9, no. 1, Article ID 016003, 2012.

[41] R. Ferraldeschi, A. McDaniel, R. Krupa et al., "CK- and small nuclear size circulating tumor cell (CTCs) phenotypes in metastatic castration-resistant prostate cancer (mCRPC)," Journal of Clinical Oncology, vol. 32, no. 4, pp. 209-209, 2014.

[42] N. Aceto, A. Bardia, D. T. Miyamoto et al., "Circulating tumor cell clusters are oligoclonal precursors of breast cancer metastasis," Cell, vol. 158, no. 5, pp. 1110-1122, 2014.

[43] I. Cima, S. L. Kong, D. Sengupta et al., "Tumor-derived circulating endothelial cell clusters in colorectal cancer," Science Translational Medicine, vol. 8, no. 345, Article ID 345ra89, 2016.

[44] R. A. Ghossein, S. Bhattacharya, and J. Rosai, "Molecular detection of micrometastases and circulating tumor cells in solid tumors," Clinical Cancer Research, vol. 5, no. 8, pp. 19501960, 1999.

[45] M. C. Miller, G. V. Doyle, and L. W. Terstappen, "Significance of circulating tumor cells detected by the cellsearch system in patients with metastatic breast colorectal and prostate cancer," Journal of Oncology, vol. 2010, Article ID 617421, 8 pages, 2010.

[46] C. Alix-Panabières and K. Pantel, "Circulating tumor cells: liquid biopsy of cancer," Clinical Chemistry, vol. 59, no. 1, pp. 110-118, 2013.

[47] L. H. A. Broersen, G. W. Van Pelt, R. A. E. M. Tollenaar, and W. E. Mesker, "Clinical application of circulating tumor cells in breast cancer," Cellular Oncology, vol. 37, no. 1, pp. 9-15, 2014.

[48] E. S. Lianidou and A. Markou, "Circulating tumor cells in breast cancer: Detection systems, molecular characterization, and future challenges," Clinical Chemistry, vol. 57, no. 9, pp. 1242-1255, 2011.

[49] Veridex CellSearch Website, 2017.

[50] M. Hegemann, A. Stenzl, J. Bedke, K. N. Chi, P. C. Black, and T. Todenhöfer, "Liquid biopsy: ready to guide therapy in advanced prostate cancer?” BJU International, vol. 118, no. 6, pp. 855-863, 2016.

[51] A. Markou, M. Zavridou, I. Sourvinou et al., "Direct comparison of metastasis-related miRNAs expression levels in circulating tumor cells, corresponding plasma, and primary tumors of breast cancer patients," Clinical Chemistry, vol. 62, no. 7, pp. 1002-1011, 2016.

[52] S. D. Mikolajczyk, L. S. Millar, P. Tsinberg et al., "Detection of EpCAM-negative and cytokeratin-negative circulating tumor cells in peripheral blood," Journal of Oncology, vol. 2011, Article ID 252361, 10 pages, 2011.
[53] K. Pachmann, "Current and potential use of MAINTRAC method for cancer diagnosis and prediction of metastasis," Expert Review of Molecular Diagnostics, vol. 15, no. 5, pp. 597605, 2015.

[54] K. Pachmann, O. Camara, A. Kavallaris et al., "Monitoring the response of circulating epithelial tumor cells to adjuvant chemotherapy in breast cancer allows detection of patients at risk of early relapse," Journal of Clinical Oncology, vol. 26, no. 8, pp. 1208-1215, 2008.

[55] K. Pachmann, O. Camara, A. Kavallaris, U. Schneider, S. Schünemann, and K. Höffken, "Quantification of the response of circulating epithelial cells to neodadjuvant treatment for breast cancer: a new tool for therapy monitoring," Breast cancer research, vol. 7, no. 6, pp. R975-R979, 2005.

[56] O. Camara, M. Rengsberger, A. Egbe et al., "The relevance of circulating epithelial tumor cells (CETC) for therapy monitoring during neoadjuvant (primary systemic) chemotherapy in breast cancer," Annals of Oncology, vol. 18, no. 9, pp. 1484-1492, 2007.

[57] K. Pachmann, O. Camara, A. Kohlhase et al., "Assessing the efficacy of targeted therapy using circulating epithelial tumor cells (CETC): The example of SERM therapy monitoring as a unique tool to individualize therapy," Journal of Cancer Research and Clinical Oncology, vol. 137, no. 5, pp. 821-828, 2011.

[58] K. Pachmann, O. Camara, T. Kroll et al., "Efficacy control of therapy using circulating epithelial tumor cells (CETC) as "liquid biopsy": Trastuzumab in HER2/neu-positive breast carcinoma," Journal of Cancer Research and Clinical Oncology, vol. 137, no. 9, pp. 1317-1327, 2011.

[59] K. Hekimian, S. Meisezahl, K. Trompelt, C. Rabenstein, and K. Pachmann, "Epithelial Cell Dissemination and Readhesion: Analysis of Factors Contributing to Metastasis Formation in Breast Cancer," ISRN Oncology, vol. 2012, Article ID 601810, 8 pages, 2012.

[60] A. Rolle, R. Günzel, U. Pachmann, B. Willen, K. Höffken, and K. Pachmann, "Increase in number of circulating disseminated epithelial cells after surgery for non-small cell lung cancer monitored by MAINTRAC is a predictor for relapse: a preliminary report," World Journal of Surgical Oncology, vol. 3, article 18, 2005.

[61] O. Camara, A. Kavallaris, H. Nöschel, M. Rengsberger, C. Jörke, and K. Pachmann, "Seeding of epithelial cells into circulation during surgery for breast cancer: the fate of malignant and benign mobilized cells," World Journal of Surgical Oncology, vol. 4, article 67, 2006.

[62] K. Hoshino, Y.-Y. Huang, N. Lane et al., "Microchip-based immunomagnetic detection of circulating tumor cells," Lab on a Chip - Miniaturisation for Chemistry and Biology, vol. 11, no. 20, pp. 3449-3457, 2011.

[63] P. Chen, Y.-Y. Huang, K. Hoshino, and X. Zhang, "Multiscale immunomagnetic enrichment of circulating tumor cells: From tubes to microchips," Lab on a Chip - Miniaturisation for Chemistry and Biology, vol. 14, no. 3, pp. 446-458, 2014.

[64] Y.-Y. Huang, K. Hoshino, P. Chen et al., "Immunomagnetic nanoscreening of circulating tumor cells with a motion controlled microfluidic system," Biomedical Microdevices, vol. 15, no. 4, pp. 673-681, 2013.

[65] K. Hoshino, P. Chen, Y.-Y. Huang, and X. Zhang, "Computational analysis of microfluidic immunomagnetic rare cell separation from a particulate blood flow," Analytical Chemistry, vol. 84, no. 10, pp. 4292-4299, 2012. 
[66] S. Nagrath, L. V. Sequist, S. Maheswaran et al., "Isolation of rare circulating tumour cells in cancer patients by microchip technology," Nature, vol. 450, no. 7173, pp. 1235-1239, 2007.

[67] N. Scheumann, T. Gorges, N. Penkalla et al., "50P enumeration and molecular characterization of circulating tumor cells in lung cancer patients using the gilupi cellcollector, an effective in vivo device for capturing CTCs," Annals of Oncology, vol. 26, no. suppl 1, pp. i14-i14, 2015.

[68] P. Chen, Y.-Y. Huang, K. Hoshino, and J. X. J. Zhang, "Microscale magnetic field modulation for enhanced capture and distribution of rare circulating tumor cells," Scientific Reports, vol. 5, article no. 8745, 2015.

[69] Y.-Y. Huang, P. Chen, C.-H. Wu et al., "Screening and Molecular Analysis of Single Circulating Tumor Cells Using Micromagnet Array," Scientific Reports, vol. 5, Article ID 16047, 2015.

[70] P. Chen, Y.-Y. Huang, G. Bhave, K. Hoshino, and X. Zhang, "Inkjet-Print Micromagnet Array on Glass Slides for Immunomagnetic Enrichment of Circulating Tumor Cells," Annals of Biomedical Engineering, vol. 44, no. 5, pp. 1710-1720, 2016.

[71] J. Nieva, M. Wendel, M. S. Luttgen et al., "High-definition imaging of circulating tumor cells and associated cellular events in non-small cell lung cancer patients: a longitudinal analysis," Physical Biology, vol. 9, no. 1, Article ID 016004, 2012.

[72] I. Desitter, B. S. Guerrouahen, N. Benali-Furet et al., "A new device for rapid isolation by size and characterization of rare circulating tumor cells," Anticancer Research, vol. 31, no. 2, pp. 427-441, 2011.

[73] http://www.gilupi.de.

[74] N. Saucedo-Zeni, S. Mewes, R. Niestroj et al., "A novel method for the in vivo isolation of circulating tumor cells from peripheral blood of cancer patients using a functionalized and structured medical wire," International Journal of Oncology, vol. 41, no. 4, pp. 1241-1250, 2012.

[75] K. Luecke, L. Gasiorowski, S. Herold, N. Brychta, G. Gallerani, and T. Krahn, "The GILUPI CellCollector as an in vivo tool for circulating tumor cell enumeration and molecular characterization in lung cancer patients," American Society of Clinical Oncology, vol. 33, no. 15, 2015.

[76] http://www.viatarctcsolutions.com/.

[77] A. Markou, A. Strati, N. Malamos, V. Georgoulias, and E. S. Lianidou, "Molecular characterization of circulating tumor cells in breast cancer by a liquid bead array hybridization assay," Clinical Chemistry, vol. 57, no. 3, pp. 421-430, 2011.

[78] X. H. Zhang, X. Jin, S. Malladi et al., "Selection of bone metastasis seeds by mesenchymal signals in the primary tumor stroma," Cell, vol. 154, no. 5, pp. 1060-1073, 2013.

[79] N. López-Riquelme, A. Minguela, F. Villar-Permuy et al., "Imaging cytometry for counting circulating tumor cells: Comparative analysis of the CellSearch vs ImageStream systems," APMIS, vol. 121, no. 12, pp. 1139-1143, 2013.

[80] M. Dao, S. Suresh, T. J. Huang et al., "Acoustic separation of circulating tumor cells," Proceedings of the National Academy of Sciences of the United States of America, vol. 112, no. 16, pp. 49704975, 2015.

[81] https://www.thermofisher.com.

[82] S. Meng, D. Tripathy, S. Shete et al., "HER-2 gene amplification can be acquired as breast cancer progresses," Proceedings of the National Academy of Sciences of the United States of America, vol. 101, no. 25, pp. 9393-9398, 2004.

[83] G. Attard, J. F. Swennenhuis, D. Olmos et al., "Characterization of ERG, AR and PTEN gene status in circulating tumor cells from patients with castration-resistant prostate cancer," Cancer Research, vol. 69, no. 7, pp. 2912-2918, 2009.

[84] D. Hayes, T. Walker, B. Singh et al., "Monitoring expression of HER-2 on circulating epithelial cells in patients with advanced breast cancer," International Journal of Oncology, vol. 21, no. 5, pp. 1111-1117, 2002.

[85] S. M. O’Hara, J. G. Moreno, D. R. Zweitzig, S. Gross, L. G. Gomella, and L. W. M. M. Terstappen, "Multigene reverse transcription-PCR profiling of circulating tumor cells in hormone-refractory prostate cancer," Clinical Chemistry, vol. 50, no. 5, pp. 826-835, 2004.

[86] J. S. De Bono, G. Attard, A. Adjei et al., "Potential applications for circulating tumor cells expressing the insulin-like growth factor-I receptor," Clinical Cancer Research, vol. 13, no. 12, pp. 3611-3616, 2007.

[87] D. Marrinucci, K. Bethel, M. Luttgen, R. H. Bruce, J. Nieva, and P. Kuhn, "Circulating tumor cells from well-differentiated lung adenocarcinoma retain cytomorphologic features of primary tumor type," Archives of Pathology and Laboratory Medicine, vol. 133, no. 9, pp. 1468-1471, 2009.

[88] D. C. Danila, G. Heller, G. A. Gignac et al., "Circulating tumor cell number and prognosis in progressive castration-resistant prostate cancer," Clinical Cancer Research, vol. 13, no. 23, pp. 7053-7058, 2007.

[89] J. S. de Bono, H. I. Scher, R. B. Montgomery et al., "Circulating tumor cells predict survival benefit from treatment in metastatic castration-resistant prostate cancer," Clinical Cancer Research, vol. 14, no. 19, pp. 6302-6309, 2008.

[90] O. B. Goodman Jr., L. M. Fink, J. T. Symanowski et al., "Circulating tumor cells in patients with castration-resistant prostate cancer baseline values and correlation with prognostic factors," Cancer Epidemiology Biomarkers and Prevention, vol. 18, no. 6, pp. 1904-1913, 2009.

[91] H. I. Scher, X. Jia, J. S. de Bono et al., "Circulating tumour cells as prognostic markers in progressive, castration-resistant prostate cancer: a reanalysis of IMMC38 trial data," The Lancet Oncology, vol. 10, no. 3, pp. 233-239, 2009.

[92] D. Olmos, H. T. Arkenau, J. E. Ang et al., "Circulating tumour cell (CTC) counts as intermediate end points in castrationresistant prostate cancer (CRPC): a single-centre experience," Annals of Oncology, vol. 20, no. 1, pp. 27-33, 2009.

[93] J. Y. Joung, K. S. Cho, J. E. Kim et al., "Prostate stem cell antigen mRNA in peripheral blood as a potential predictor of biochemical recurrence in high-risk prostate cancer," Journal of Surgical Oncology, vol. 101, no. 2, pp. 145-148, 2010.

[94] F. A. W. Coumans, C. J. M. Doggen, G. Attard, J. S. de Bono, and L. W. M. M. Terstappen, "All circulating EpCAM+CK+CD45objects predict overall survival in castration-resistant prostate cancer," Annals of Oncology, vol. 21, no. 9, pp. 1851-1857, 2010.

[95] J. Y. Joung, K. S. Cho, H. S. Chung et al., "Prostate specific membrane antigen mRNA in blood as a potential predictor of biochemical recurrence after radical prostatectomy," Journal of Korean Medical Science, vol. 25, no. 9, pp. 1291-1295, 2010.

[96] M. H. Strijbos, J. W. Gratama, P. I. M. Schmitz et al., "Circulating endothelial cells, circulating tumour cells, tissue factor, endothelin-1 and overall survival in prostate cancer patients treated with docetaxel," European Journal of Cancer, vol. 46, no. 11, pp. 2027-2035, 2010.

[97] D. C. Danila, A. Anand, C. C. Sung et al., "TMPRSS2-ERG Status in circulating tumor cells as a predictive biomarker of sensitivity in castration-resistant prostate cancer patients 
treated with abiraterone acetate," European Urology, vol. 60, no. 5, pp. 897-904, 2011.

[98] H. I. Scher, M. R. Smith, C. Sweeney, P. G. Corn, C. Logothetis, N. J. Vogelzang et al., "An exploratory analysis of bone scan lesion area (BSLA), circulating tumor cell (CTC) change, pain reduction, and overall survival (OS) in patients (pts) with castration-resistant prostate cancer (CRPC) treated with cabozantinib (cabo): Updated results of a phase II nonrandomized expansion (NRE) cohort," American Society of Clinical Oncology, vol. 31, no. 15, p. 5026, 2013.

[99] M. Thalgott, B. Rack, T. Maurer et al., "Detection of circulating tumor cells in different stages of prostate cancer," Journal of Cancer Research and Clinical Oncology, vol. 139, no. 5, pp. 755763, 2013.

[100] T. Okegawa, N. Itaya, H. Hara, M. Tambo, and K. Nutahara, "Circulating tumor cells as a biomarker predictive of sensitivity to docetaxel chemotherapy in patients with castration-resistant prostate cancer," Anticancer Research, vol. 34, no. 11, pp. 67056710, 2014.

[101] D. C. Danila, A. Anand, N. Schultz et al., "Analytic and clinical validation of a prostate cancer-enhanced messenger RNA detection assay in whole blood as a prognostic biomarker for survival," European Urology, vol. 65, no. 6, pp. 1191-1197, 2014.

[102] A. Goldkorn, B. Ely, D. I. Quinn et al., "Circulating tumor cell counts are prognostic of overall survival in SWOG S0421: A phase III trial of docetaxel with or without atrasentan for metastatic castration-resistant prostate cancer," Journal of Clinical Oncology, vol. 32, no. 11, pp. 1136-1142, 2014.

[103] E. S. Antonarakis, C. Lu, H. Wang, B. Luber, M. Nakazawa, J. C. Roeser et al., "AR-V7 and resistance to enzalutamide and abiraterone in prostate cancer," New England Journal of Medicine, vol. 371, pp. 1028-1038, 2014.

[104] K. Chang, Y.-Y. Kong, B. Dai et al., "Combination of circulating tumor cell enumeration and tumor marker detection in predicting prognosis and treatment effect in metastatic castrationresistant prostate cancer," Oncotarget, vol. 6, no. 39, pp. 4182541836, 2015.

[105] H. I. Scher, G. Heller, A. Molina et al., "Circulating tumor cell biomarker panel as an individual-level surrogate for survival in metastatic castration-resistant prostate cancer," Journal of Clinical Oncology, vol. 33, no. 12, pp. 1348-1355, 2015.

[106] M. Fleisher, DC. Danila, K. Fizazi, M. Hirmand, B. Selby, and D. Phung, "Circulating tumor cell (CTC) enumeration in men with metastatic castration-resistant prostate cancer (mCRPC) treated with enzalutamide post-chemotherapy (phase 3 AFFIRM study)," American Society of Clinical Oncology, vol. 33, 15_suppl, 2015.

[107] M. Thalgott, B. Rack, M. Eiber et al., "Categorical versus continuous circulating tumor cell enumeration as early surrogate marker for therapy response and prognosis during docetaxel therapy in metastatic prostate cancer patients," BMC cancer, vol. 15, p. 458, 2015.

[108] D. Lorente, D. Olmos, J. Mateo, D. Bianchini, G. Seed, and P. Flohr, "Early CTC decline as a biomarker of response to treatment in castration-resistant prostate cancer (CRPC): Analysis of the COU-AA-301 and IMMC38 trials," American Society of Clinical Oncology, vol. 33, 15_suppl, 2015.

[109] M. Crespo, G. Van Dalum, R. Ferraldeschi et al., "Androgen receptor expression in circulating tumour cells from castrationresistant prostate cancer patients treated with novel endocrine agents," British Journal of Cancer, vol. 112, no. 7, pp. 1166-1174, 2015.
[110] W. Onstenk, A. M. Sieuwerts, J. Kraan et al., "Efficacy of Cabazitaxel in Castration-resistant Prostate Cancer Is Independent of the Presence of AR-V7 in Circulating Tumor Cells," European Urology, vol. 68, no. 6, pp. 939-945, 2015.

[111] E. S. Antonarakis, C. Lu, B. Luber et al., "Androgen receptor splice variant 7 and efficacy of taxane chemotherapy in patients with metastatic castration-resistant prostate cancer," JAMA Oncology, vol. 1, no. 5, pp. 582-591, 2015.

[112] R. L. Bitting, P. Healy, S. Halabi, D. J. George, M. Goodin, and A. J. Armstrong, "Clinical phenotypes associated with circulating tumor cell enumeration in metastatic castration-resistant prostate cancer," Urologic Oncology: Seminars and Original Investigations, vol. 33, no. 3, pp. 110-110.e9, 2015.

[113] D. Lorente, D. Olmos, J. Mateo et al., "Decline in Circulating Tumor Cell Count and Treatment Outcome in Advanced Prostate Cancer," European Urology, vol. 70, no. 6, pp. 985-992, 2016.

[114] N. J. Vogelzang, K. Fizazi, J. M. Burke et al., "Circulating Tumor Cells in a Phase 3 Study of Docetaxel and Prednisone with or without Lenalidomide in Metastatic Castration-resistant Prostate Cancer," European Urology, vol. 71, no. 2, pp. 168-171, 2017.

[115] H. Tsumura, T. Satoh, H. Ishiyama et al., "Perioperative search for circulating tumor cells in patients undergoing prostate brachytherapy for clinically nonmetastatic prostate cancer," International Journal of Molecular Sciences, vol. 18, no. 1, article no. 128, 2017.

[116] B. Viswanath and S. Kim, "Recent insights into the development of nanotechnology to detect circulating tumor cells," TrAC Trends in Analytical Chemistry, vol. 82, pp. 191-198, 2016.

[117] H. I. Scher, D. Lu, N. A. Schreiber et al., "Association of ARV7 on circulating tumor cells as a treatment-specific biomarker with outcomes and survival in castration-resistant prostate cancer," JAMA Oncology, vol. 2, no. 11, pp. 1441-1449, 2016.

[118] M. Thadani-Mulero, L. Portella, S. Sun et al., "Androgen receptor splice variants determine taxane sensitivity in prostate cancer," Cancer Research, vol. 74, no. 8, pp. 2270-2282, 2014.

[119] S. Gulati, P. Martinez, T. Joshi et al., "Systematic evaluation of the prognostic impact and intratumour heterogeneity of clear cell renal cell carcinoma biomarkers," European Urology, vol. 66, no. 5, pp. 936-948, 2014.

[120] H. Butz, P. M. Szabó, R. Nofech-Mozes et al., "Integrative bioinformatics analysis reveals new prognostic biomarkers of clear cell renal cell carcinoma," Clinical Chemistry, vol. 60, no. 10, pp. 1314-1326, 2014.

[121] H. Butz, P. M. Szabó, H. W. Z. Khella, R. Nofech-Mozes, A. Patocs, and G. M. Yousef, "miRNA-target network reveals miR-124as a key miRNA contributing to clear cell renal cell carcinoma aggressive behaviour by targeting CAV1 and FLOT1," Oncotarget, vol. 6, no. 14, pp. 12543-12557, 2015.

[122] M. Lin, J.-F. Chen, Y.-T. Lu et al., "Nanostructure embedded microchips for detection, isolation, and characterization of circulating tumor cells," Accounts of Chemical Research, vol. 47, no. 10, pp. 2941-2950, 2014. 


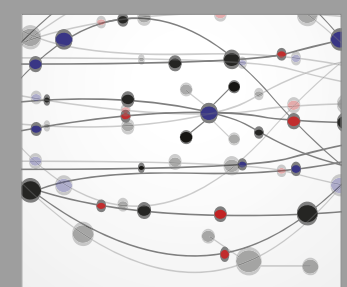

The Scientific World Journal
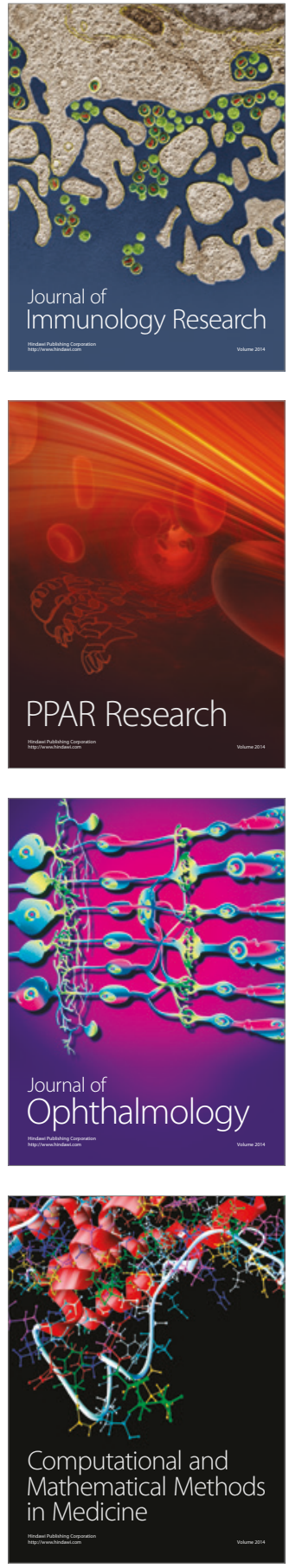

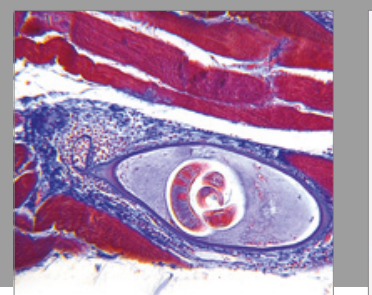

Gastroenterology Research and Practice
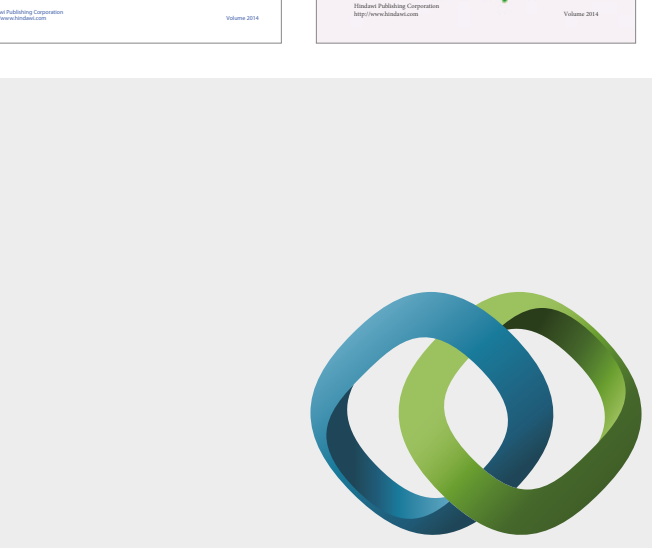

\section{Hindawi}

Submit your manuscripts at

https://www.hindawi.com
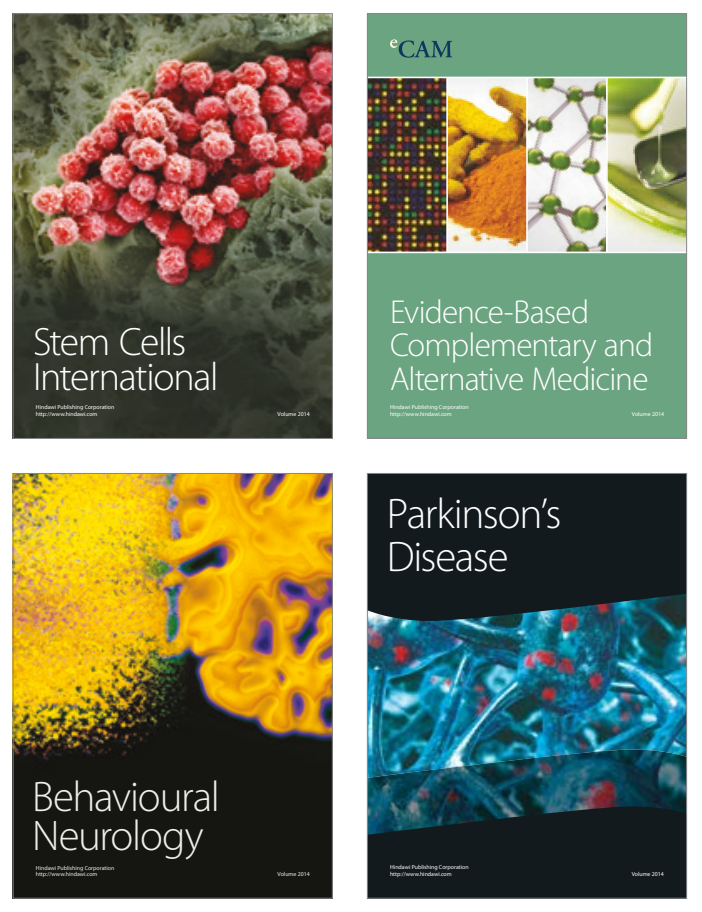
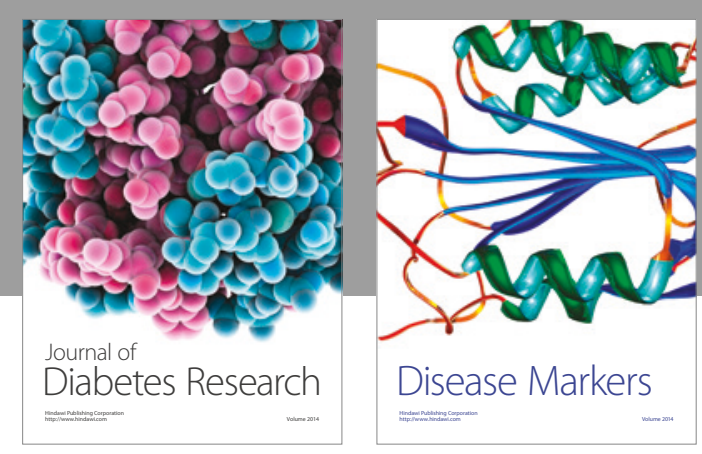

Disease Markers
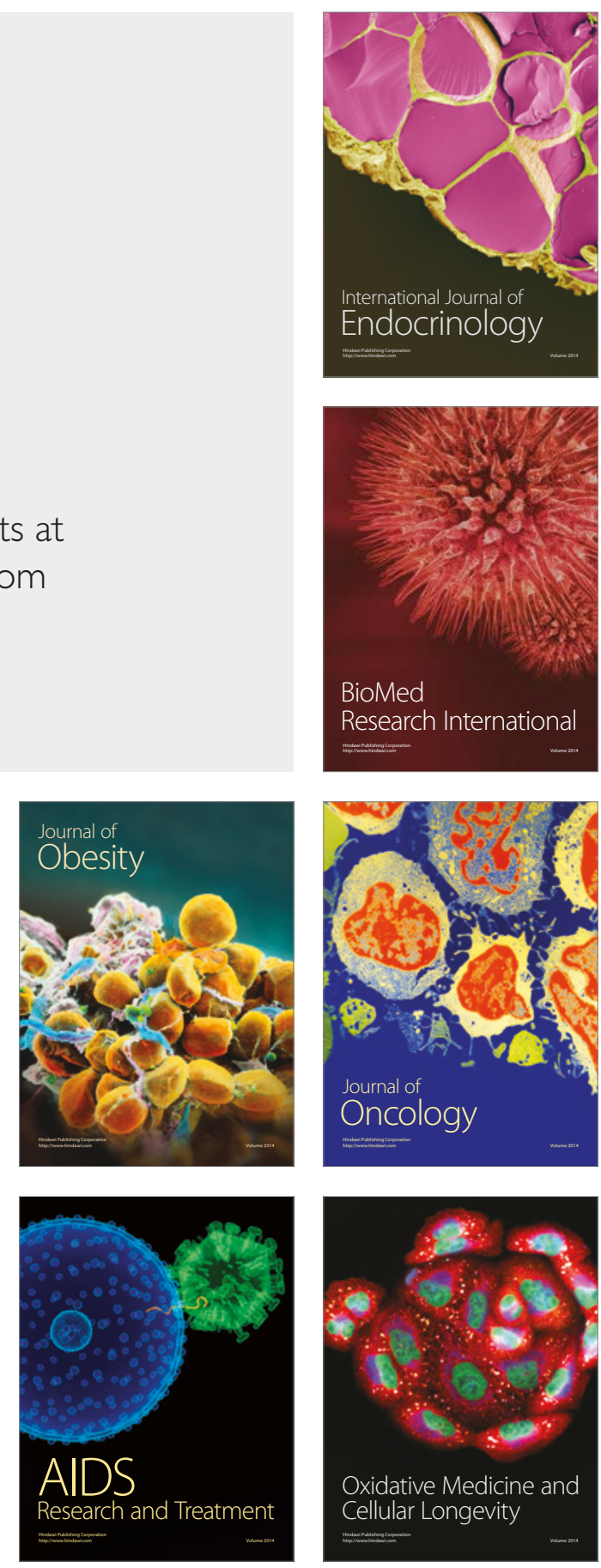